\title{
Effect of puberty on rates of bone growth and mineralisation
}

\author{
With observations in male delayed puberty
}

S. KRABBE, C. CHRISTIANSEN, P. RØDBRO, AND I. TRANSBØL

Children's Hospital, Fuglebakken, Copenhagen, Department of Clinical Chemistry, Glostrup Hospital, Department of Clinical Physiology, Aalborg Sygehus (Syd), and Division of Endocrinology, Department of Internal Medicine, Hvidovre Hospital, Denmark

SUMMARY The bone mineral content (BMC) and body height were measured in 301 normal children and adolescents aged 7-20 years, and in 8 boys with constitutional delayed puberty aged 14-17 years. Serum testosterone was measured in the last group as well as in a subpopulation of the normal children and adolescents. The growth spurt, which coincided with a steep increase of serum testosterone in boys, indicated a great change in skeletal growth and mineralisation in both sexes. After the growth spurt, linear growth slowed down considerably while bone mineralisation rose steeply. When low levels of serum testosterone were maintained, as in delayed puberty, these combined changes of skeletal growth and mineralisation did not occur. It is suggested that gonadal hormones are the true initiators of the short-lived growth spurt as well as of prolonged acceleration of bone mineralisation.

Measurement of bone mineral content (BMC) by photon absorptiometry is a precise, reliable, and easy method for assessing skeletal status (Christiansen et al., 1975a). BMC varies with age and sex and the biological variation is greatest during puberty (Christiansen et al., 1975b). In this period of outstanding growth the chronological age may be a poor indicator of physical development, as there is a wide range of growth and sexual maturation in individuals of the same age (Marshall and Tanner, 1970). In boys, serum levels of testosterone correlate well with the pubertal stage (Knorr et al., 1974), and this is a better measure of physical development than chronological age during adolescence. Determinations of serum testosterone and of various indicators of bone status have been used to assess the physical development in the adolescent, but comparisons

Department of Paediatrics, Frederiksborg Amts Hospital,
Hillerød
S. KRABBe, senior registrar
Department of Clinical Chemistry, Glostrup Hospital
C. CHRISTIANSEN, consultant physician
Department of Clinical Physiology, Aalborg Sygehus (Syd)
P. RøDBRO, consultant physician
Division of Endocrinology, Department of Internal Medicine,
Hvidovre Hospital
I. TRANSBøL, consultant physician

between $\mathrm{BMC}$ and serum testosterone have not been reported.

In order to evaluate skeletal growth and mineralisation in relation to age and development we examined BMC, serum testosterone, and body height in normal boys during childhood and adolescence, and in boys with constitutional delayed puberty.

\section{Patients and methods}

Normal children and adolescents. A total of 301 normal children and adolescents aged between 7 and 20 years participated in the study. They were randomly selected from pupils at two schools in a surburban area. Pupils below 18 years obtained written consent from their parents. All were in good health without symptoms of gastrointestinal or renal diseases. None took contraceptive pills or any other type of drug. Data on sex, age, and height are given in Figs 1 and 2.

Boys with delayed puberty. Eight boys, referred to the clinic for delayed growth or delayed pubertal development, or both, were chosen. The diagnosis was constitutional or familial delayed puberty 
(Wilkins, 1965) without signs of other endocrine disease. Based on data on pubertal changes in normal boys (Marshall and Tanner, 1970) the retardation in pubertal development was at least 2 SDs in 6 boys and between 1 and 2 SDs in 2 boys. Testicular size was within the pubertal range in all boys.

\section{Methods}

BMC was determined by direct photon absorptiometry (Christiansen et al., 1975a). The forearm was fixed in a plexiglass container filled with distilled water. A source of radiation $\left(25 \mathrm{mCi}^{125} \mathrm{I}\right)$ and a detector were placed on each side of the forearm to be examined. As these moved across the arm the transmission of photons through the bones decreased depending on the bone mineral content. Because the absorption in plexiglass, distilled water, and soft tissue is almost identical, the measurement was independent of the amount of soft tissue. The scanner started distally on the forearm, moving $4 \mathrm{~mm}$ proximally between each scan. The first scan was defined as that demonstrating a distance between radius and ulna of at least $2 \mathrm{~mm}$. The bone mineral content was expressed in arbitrary units as a mean of 6 scans on each forearm. The coefficient of variation in normal subjects is about $2 \%$.

From the 156 normal boys, a subgroup of 103 was randomly selected for determination of serum levels of testosterone. Serum testosterone was measured by radioimmunoassay including a modification of thin-layer chromatography (Pirke, 1973).

\section{Results}

Normal children and adolescents. Figs 1 and 2 give the heights and BMC values in boys and girls divided into one-year age groups. Before the growth spurt-between ages 11 and 12 years in girls, and 2 years later in boys-the mean height and BMC increments each year were similar in boys and girls. The respective height increments were $4 \cdot 5$ and $4 \cdot 7$ $\mathrm{cm}$ per year, while BMC increased very slowly, $0 \cdot 14$ and 0.09 units per year. After the growth spurt linear growth procedeed slowly at average rates of 1.5 and $0.5 \mathrm{~cm}$ per year respectively, while there was a large increase in BMC in both sexes. During this phase of development the BMC increments averaged $2 \cdot 23$ units per year in boys and 1.13 units per year in girls (Figs 1 and 2).

Fig. 3 shows the association between serum testosterone and age in the boys. A sharp increase was found at ages 13 and 14 years, simultaneous with the growth spurt (Fig. 1).
Boys with delayed puberty. For their chronological age of $15.9 \pm 0.9$ years these boys were small, $155.0 \pm 4.8 \mathrm{~cm}$, and had very low BMC values averaging $27 \cdot 2 \pm 4 \cdot 0$ units, corresponding to $66 \%$

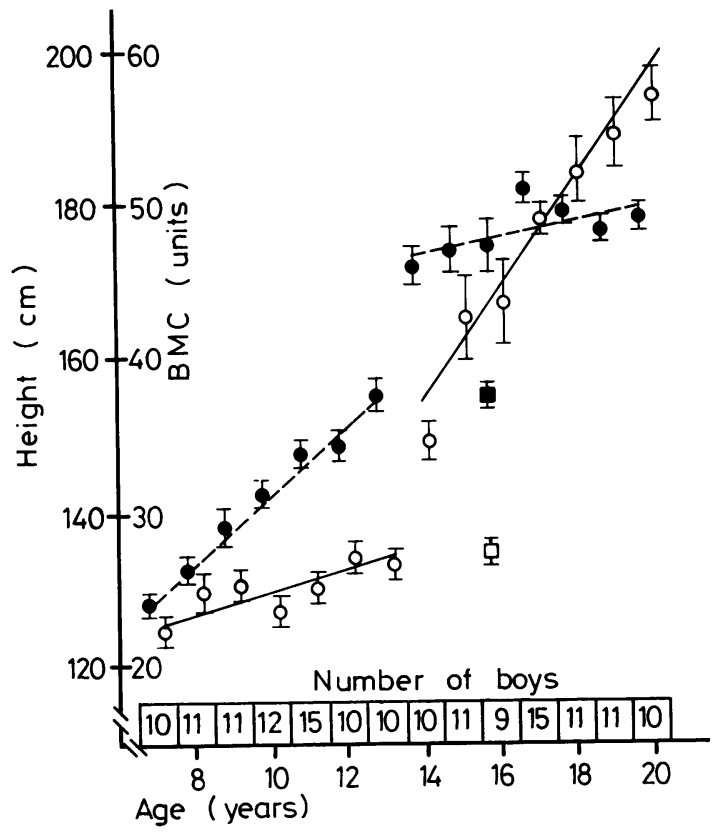

Fig. 1 Bone mineral content (0) and height (๑) as a function of age in 156 normal boys aged 7-20 years and in 8 boys with delayed puberty ( $\square$ and $\square$ ). Values given as mean $\pm S E$ of mean.



Fig. 2 Bone mineral content (0) and height (•) as a function of age in 145 girls aged 7-20 year.s. Values given as mean $\pm 1 S E$ of mean. 




Fig 3. Serum testosterone levels (๑) as a function of age in 103 normal boys aged 7-20 years and in 8 boys with delayed puberty $(\square)$. Values given as mean \pm 1 $S E$ of mean.

Conversion: SI to traditional units-testosterone $1 \mathrm{nmol} / 1 \approx 0.288 \mathrm{ng} / \mathrm{ml}$.

of age-matched normal boys. Their average level of serum testosterone was also low, $2 \cdot 8 \pm 4 \cdot 1 \mathrm{nmol} / 1$ $(0.80 \pm 1 \cdot 18 \mathrm{ng} / \mathrm{ml})$ (Fig. 3). All these values are given as mean $\pm 1 \mathrm{SD}$.

\section{Discussion}

The onset of the adolescent growth spurt is an important event in skeletal development. In addition to the rather short-lived spurt of growth, it indicates the start of a much more prolonged acceleration of bone mineralisation in both sexes. The timing within the same year of a steep increase of the serum testosterone levels in boys (Fig. 3) with the growth and mineralisation spurt suggests an important role for testosterone in the initiation of both processes and probably in the maintenance over several years of the accelerated bone mineralisation. This view is supported by our observations in boys with delayed puberty: the maintenance of low levels of serum testosterone postpones the onset of the growth and mineralisation spurt. As the peak height increment and the increase in BMC in girls occur at ages 11 to 12 years, when rising levels of plasma oestrone and oestradiol are being observed (Gupta, 1975), it also seems reasonable to assume that rising levels of these hormones serve as the initiator of both spurts in girls. Gonadal hormones may exert their effects on mineralisation through a complex of mechanisms. Firstly, these hormones may have a direct inhibiting effect on bone resorption, although data from tissue culture studies are conflicting (Atkins et al., 1972; Caputo et al., 1976). Secondly, gonadal hormones are potent stimulators of the production of the biologically active vitamin D3 metabolite, 1,25 $(\mathrm{OH})_{2} \mathrm{D}_{3}$, in birds (Tanaka et al., 1976), and have also been found to increase plasma calcitonin levels in normal man (Hillyard et al., 1978). Thirdly, androgens may also enhance the skeletal sensitivity to calcitonin, as shown in the rat (Ogata et al., 1970).

The results in the boys with delayed puberty show the importance of using proper reference materials especially in adolescents. If the BMC values are compared with those of age-matched controls, as is done conventionally for the purpose of calcium metabolic investigation, a diagnosis of severe osteopenia would be made. Therefore we suggest that BMC measurements in pubertal boys should be evaluated from testosterone levels or physical development, rather than from chronological age.

Figs 1 and 2 show that the greatest dissociation between skeletal growth and mineralisation takes place during the last years ahead of the growth and mineralisation spurt. This phenomenon may in fact explain the peak incidence of forearm fractures observed in children of 10-14 years of age (Alffram and Bauer, 1962)

\section{References}

Alffram, P-A., and Bauer, G. C. H. (1962). Epidemiology of fractures of the forearm. Journal of Bone and Joint Surgery, 44A, 105-114.

Atkins, D., Zanelli, J. M., Peacock, M., and Nordin, B. E. C. (1972). The effect of oestrogens on the response of bone to parathyroid hormone in vitro. Journal of Endocrinology, 54, 107-117.

Caputo, C. B., Meadows, D., and Raisz, L. G. (1976). Failure of estrogens and androgens to inhibit bone resorption in tissue culture. Endocrinology, 98, 1065-1068.

Christiansen, C., Rödbro, P., and Jensen, H. (1975a). Bone mineral content in the forearm measured by photon absorptiometry. Scandinavian Journal of Clinical and Laboratory Investigation, 35, 323-330.

Christiansen, C., Rödbro, P., and Thöger-Nielsen, C. (1975b). Bone mineral content and estimated total body calcium in normal children and adolescents. Scandinavian Journal of Clinical and Laboratory Investigation, 35, 507-510.

Gupta, D. (1975). Changes in the gonadal and adrenal steroid patterns during puberty. Clinics in Endocrinology and Metabolism, 4, 27-56. 
Hillyard, C. J., Stevenson, J. C., and MacIntyre, I. (1978). Relative deficiency of plasma-calcitonin in normal women. Lancet, 1, 961-962.

Knorr, D., Bidlingmaier, F., Butenandt, O., Fendel, H., and Ehrt-Wehle, R. (1974). Plasma testosterone in male puberty. Acta endocrinologica, 75, 181-194.

Marshall, W. A., and Tanner, J. M. (1970). Variations in the pattern of pubertal changes in boys. Archives of Disease in Childhood, 45, 13-23.

Ogata, E., Shimazawa, E., Suzuki, H., Yoshitoshi, Y., Asona, H., and Ando, H. (1970). Androgens and enhancement of hypocalcemic response to thyrocalcitonin in rats. Endocrinology, 87, 421-426.

Pirke, K. M. (1973). A comparison of three methods of measuring testosterone in plasma: competitive protein binding, radioimmunoassay without chromatography, and radioimmunoassay including thin layer chromatography. Acta endocrinologica, 74, 168-176.

Tanaka, Y., Castillo, L., and DeLuca, H. F. (1976). Controls of renal vitamin $\mathrm{D}$ hydroxylases in birds by sex hormones. Proceedings of the National Academy of Sciences of the United States of America, 73, 2701-2705.

Wilkins, L. (1965). The Diagnosis and Treatment of Endocrine Disorders in Childhood and Adolescence, third edition. Thomas: Springfield.

Correspondence to Dr S. Krabbe, Children's Department, Frederiksborg Amts Centralsygehus, 3400 Hillerød, Denmark.

Received 6 February 1979

The following articles will appear in future issues of this journal:

Mumps and varicella vaccines. J. A. Dudgeon.

Outpatient paediatric cardiological investigation-an alternative approach. G. J. Williams.

Effect of nasogastric tubes on nasal resistance during infancy. J. Stocks.

Lactobezoar and cows' milk protein intolerance. J. N. Lemoh and J. Watt.

Immunological abnormalities in the syndrome of poliomyelitis-like illness associated with acute bronchial asthma (Hopkins's syndrome). J. I. Manson and Y. H. Thong.

Poliomyelitis-like illness associated with asthma. H. K:son Blomquist and B. Björkstén. 